\title{
POTENTIAL CONTENT OF ENERGY MATERIAL FOR EMPOWERING ENVIRONMENTAL AWARENESS IN SCIENCE LESSON IN ELEMENTARY SCHOOL TEACHER CANDIDATE
}

\section{Siti Patonah, Sentot Budi Rahardjo, Cari, Sajidan}

Universitas Sebelas Maret

sitifatonah@upgris.ac.id

\section{Article History}

accepted 09/07/2018

approved 01/08/2018

published 17/09/2018

\section{Keywords}

Content of energy, empowering,

environmental awareness, elementary school teacher candidate

\begin{abstract}
Environmental damage is increasingly worrisome, requiring basic handling. Among the important roles in the process of preparing human resources that have environmental concerns is through education. Especially in basic education. Therefore preparing prospective elementary school teachers who can undertake the task of preparing future resources that have environmental concerns becomes an urgent need. The process of preparing teachers to have environmental concerns can be taught through energy learning. The subject / unit about energy is an option because the discussion is very close to everyday life.
\end{abstract}

Social, Humanities, and Education Studies (SHEs): Conference Series https://jurnal.uns.ac.id/shes 


\section{PENDAHULUAN}

Ketidakpekaan terhadap masalah lingkungan menjadi masalah besar(Uzunöz \& Demirhan, 2017) baik skala lokal, maupun global. Padahal kerusakan alam sudah semakin mengawatirkan. Mengubah perilaku diyakini sebagai suatu cara yang efektif untuk dapat berkontribusi pada masalah lingkungan yang dihadapi. Berkaitan dengan pengubahan perilaku, guru sebagai garda terdepan dalam pembelajaran memiliki peran yang strategis dalam menciptakan kesadaran lingkungan, melalui pendidikan. Pendidikan merupakan jalur pertahanan pertama untuk menyebarkan kesadaran terhadap lingkungan dan mulai mempengaruhi tingkah laku dan sikap siswa ke arah yang lebih baik sebagai bekal di masa depan (Freije, Hussain, \& Salman, 2015). Pendidikan merupakan faktor dasar dalam pengembangan masyarakat dan negara (Systems \& Sciences, 2017);(Karataş, 2014);(Koruoglu, Ugulu, \& Yorek, 2015). Pendidikan yang berhasil dapat dilihat dari indikator pribadi yang ada di dalamnya, salah satunya adalah indikator kepedulian terhadap lingkungan yang dikenal dengan 'environmental literacy'. Environmental literacy didefinisikan sebagai pengetahuan yang tepat yang dimiliki oleh seseorang terhadap lingkungan dan permasalahannya sehingga dapat diwujudkan dalam kegiatan nyata yang tepat dalam kehidupannya sehari-hari (Saribas, Teksoz, \& Ertepinar, 2014). Environmental literacy disebut sebagai salah satu indikator keberhasilan dari pendidikan lingkungan yang telah dilaksanakan. Melatihkan environmental literacy sejak dini menjadi kebutuhan mendasar untuk masyarakat masa depan yang lebih baik.

Untuk dapat menghasilkan masyarakat yang memiliki environmental literacy diperlukan sumber daya guru yang memiliki environmental literacy yang bagus juga. Calon guru, terutama yang memiliki kepekaan terhadap perlindungan lingkungan, lebih mudah memberikan penjelasan kepada siswanya mengenai kontribusi yang signifikan dari setiap individu terhadap kelestarian lingkungan untuk kelangsungan hidupnya (Yumuşak, Sargın, Baltacı, \& Kelani, 2016). Terutama pendidikan paling dini di tingkat formal (SD). Jenjang sekolah dasar menjadi penentu praktik-praktik pembiasaan yang bermanfaat pada jenjang berikutnya, bahkan sepanjang hidup. Pengenalan tentang menjaga lingkungan sangat penting diajarkan sejak dini. Peran guru sangat menentukan keberhasilan menjaga lingkungan yang bermuara pada sikap peduli lingkungan. Penyiapan guru SD untuk dapat membiasakan siswanya peduli terhadap lingkungan menjadi hal yang perlu terus diuayakan. Pendidikan memegang peranan penting untuk meningkatkan kepedulian lingkungan dari mahasiswa (Freije et al., 2015);(Yuan, She, Li, Zhang, \& Wu, 2016), atmosfere pendidikan membantu mahasiswa dapat membiasakan diri dalam membangun kepedulian lingkungan (Toom, Pietarinen, Soini, \& Pyhältö, 2017). Kampus sebagai salah satu "small city"(Alshuwaikhat \& Abubakar, 2008);(Sarsour \& Ayoub, 2015), tempat bergabungnya semua budaya, kebiasaan, pengetahuan, dan aktivitas kompleks merupakan sarana yang cocok untuk mempersiapkan masyarakat yang memiliki kesadaran tinggi terhadap lingkungan. Praktik-praktik kepedulian lingkungan muncul berawal dari pengetahuan yang dimiliki oleh mahasiswa. Pengetahuan kemudian menggerakkan motoriknya melakukan aktivitas nyata, tidak sekedar berhenti sebagai pengetahuan (Mei, Wai, \& Ahamad, 2016), sehingga melahirkan kesadaran untuk senantiasa peduli terhadap lingkungan.

Di satu sisi, kebutuhan manusia akan energi meningkat lebih tinggi melebihi pertambahan jumlah penduduk. Hal ini dikarenakan kebutuhan seseorang akan energi dalam kehidupan sehari-hari menjadi penanda masih adanya kehidupan. Pemahaman yang betul dan benar tentang energi (energy literacy) diharapkan dapat membantu setiap individu untuk mengambil keputusan yang bijak berkaitan dengan penggunaan energi dalam kehidupan sehari-hari (Stern, Young, \& Druckman, 1992);(Ostrom et al., 
2002);(Ostrom et al., 2002);(NRC, 2006). Oleh karenanya, pada kesempatan kali ini penulis akan memaparkan potensi konten materi energi dalam menumbuhkan kepedulian lingkungan. Masalah yag dibahas pada artikel ini adalah: Apakah pendidikan lingkungan hidup itu? Bagaimana posisi konten energi dalam kurikulum pendidikan lingkungan hidup? Bagaiamana kurikulum di Indonesia membahas tentang energi dan lingkungan? Serta, bagaimana potensi materi energi untuk menumbuhkan kepedulian lingkungan?

\section{PEMBAHASAN}

\section{Pendidikan Lingkungan Hidup}

Pendidikan lingkungan hidup adalah pengetahuan tentang ekologi dan sistem sosial dengan memanfaat berbagai disiplin ilmu (Ostrom et al., 2002). Pendidikan ini sangatlah penting diberikan oleh setiap individu untuk dapat membuat keputusan yang tepat dalam menyelesaikan masalah-masalah yang berhubungan dengan lingkungan(Palmer, 1998). Pendidikan yang diperolehnya kemudian diterapkan dalam kehidupan sehari-hari(Hadzigeorgiou \& Skoumios, 2013);(Fidan \& Ay, 2016);(Jones, 2013). Mengajarkan kepedulian lingkungan pada sekolah formal dapat dilatihkan sejak kecil dengan tema-tema yang tidak jauh dari kondisi lokal. Pemahaman yang utuh bahwa kegiatan yang bersifat lokal dapat mempengaruhi sistem secara global merupakan salah satu bagian penting perlu disampaikan kepada siswa (Stern et al., 1992);(Simon, 1973);(Ostrom et al., 2002). Setidaknya ada 11 tema yang dapat digunakan untuk melatihkan kepedulian lingkungan(Palmer, 1998), yaitu: (1) Area and location; (2) Atmosfer and cosmos; (3) Landforms, soils, and minerals; (4) Plants and animals; (5) Water; (6) People; (7) Social organization; (8) Economics; (9) Aesthetics, ethics, literacy, numeracy; (10) Builts Environment; and (11) Energy. Energi menjadi pokok bahasan esensial untuk dijadikan bagian dalam tema yang bertujuan melatihkan kepedulian lingkungan karena mengkait dengan banyak hal (Palmer, 1998);(Ostrom et al., 2002).

\section{Konten materi energi}

Pembahasan konten energi yang dapat digunakan untuk melatihkan kepedulian lingkungan khususnya adalah pada pembahasan konservasi energi. Bahkan ada yang menyebutnya sebagai literacy energy.Setidaknya ada 6 tujuan dari pendidikan tentang energi (Bauman \& Petrock, 1981), yaitu:

a. Memungkinkan orang untuk memahami tentang sifat dan pentingnya energi

b. Memberikan informasi tentang mengubah pasokan dan faktor kebutuhan dari berbagai sumber energi

c. Mempersiapkan orang untuk mempertimbangkan implikasi sumber energi yang berada di tingkat daerah, nasional dan internasional

d. Menyediakan informasi tentang konservasi energi

e. Mempersiapkan orang baik individu maupun keputusan masyarakat berkaitan dengan gangguan pasokan energi

f. Mempersiapkan orang untuk memilih karir yang berkaitan dengan perolehan sumber-sumber energi dan menjadi lebih sadar dalam penggunaan energi pada karir yang lain.

Energi adalah topik yang relevan untuk dapat menumbuhka kepedulian lingkungan, karena ia menyerap sebagian besar aspek kehidupan sehari-hari di masyarakat industri (Bauman \& Petrock, 1981);(Kulo \& Bodzin, 2013). Beberapa pembahasan energi dan konservasinya meliputi sumber energi yang dapat diperbarui dan tidak 
dapat diperbaharui(Kulo \& Bodzin, 2013);(Abu Md Abdul Wadud, Tousif Zaman, Rabbee, \& Rajibur Rahman, 2013);(Alrikabi, 2014);(Systems \& Sciences, 2017) penjelasannya adalah sebagai berikut:

a. Sumber energi yang tidak dapat diperbarui, yaitu sumber energi yang terbatas dan akhirnya akan habis

b. Sumber energi yang dapat diperbarui, yaitu energi dihasilkan dari proses alam yang bisa diganti atau dipulihkan, yang termasuk dalam kelompok ini adalah:

1) Energi matahari, Energi matahari yang sampai ke benua jumlahnya lebih dari 200 kali dari seluruh energi komersial tahunan yang dibutuhkan manusia. Dibagi dalam 2 tipe yaitu aktif dan pasif. Pasif berarti: penggunaan energi panas langsung dan tidak langsung dari sinar matahari. Sedangkan aktif, berarti penggunaan elektromagnetik matahari radiasi dalam menghasilkan energi listrik.

2) Energi angin, lokasi turbin menentukan banyak sedikitnya energi yang dihasilkan. Energi angin tidak menghasilkan polusi udara atau air, tidak melibatkan zat beracun atau berbahaya, dan tidak menimbulkan ancaman terhadap keamanan publik

3) Energi biomassa, merupakan sumber energi yang dihasilkan dari basis pertanian. Merupakan bagian energi terbarukan yang terbesar, karena di alam terdapat melimpah.

4) Energi pasang surut air laut, Pergerakan air di bagian depan pantai dalam energi kinetik yang bisa diubah menjadi energi listrik

5) Energi geothermal, energi dari dalam bumi

6) Energi sampah (WTE=waste to energy). Sampah yang melimpah sebagai konskuensi aktivitas manusia jika dikelola dengan baik dapat menjadi sumber energi terbarukan.

3. Ketersediaan pendidikan lingkungan hidup pada setiap jenjang pendidikan di Indonesia

Kurikulum pendidikan lingkungan hidup pada tingkat sekolah dasar berdasarkan peraturan menteri pendidikan dan kebudayaan No. 24 lampiran 5 ditunjukkan pada tabel 1. Berdasarkan tabel 1, maka dapat disimpulkan bahwa sebaran materi khusus tentang lingkungan hidup dalam mata pelajaran IPA tidak ada, mengkait dengan tema/ pokok bahasan. Untuk kelas IV dari 16 kompetensi dasar yang ada terdapat 4 standar kompetensi yang mengarah pada tema lingkungan (25\%); untuk kelas $\mathrm{V}$ terdapat 18 kompetensi dasar ada 2 tema yang berkaitan dengan lingkungan (11\%), sedangkan untuk kelas VI sama dengan kelas IV untuk jumlah persentase tema tentang lingkungan. Sedangkan yang berkaitan dengan khusus energi hanya ada pada pembelajaran kelas $V$ sekolah dasar. Sehingga kebutuhan guru untuk dapat mengemas pembelajaran yang dapat menumbuhkan kepedulian lingkungan menjadi kepentingan utama untuk dapat berperan serta menjaga kelestarian lingkungan.

Pada jenjang SMP, Kurikulum pendidikan lingkungan hidup masih terintegrasi dalam subjek mata pelajaran IImu Pengetahuan Alam (IPA). Dari 22 kompetensi dasar mata pelajaran IPA pada tingkat VII hanya ada 4 kompetensi dasar yang berkaitan dengan tema lingkungan hidup (18\%), pada tingkat VIII dari 24 kompetensi dasar tidak ada satupun yang membahas tentang lingkungan hidup, sedangkan di tingkat IX hanya 2 kompetensi dasar yang membahas tentang lingkungan hidup, dari 20 kompetensi dasar yang ada (10\%) (Patonah, Nuvitalia, \& Saptaningrum, 2017). Pada tingkat SMA, mata pelajaran IPA terbagi dalam 3 domain, yaitu Biologi, Fisika, dan Kimia. Secara 
umum sebaran tema tentang lingkungan ditunjukkan pada tabel 2. Lagi-lagi guru harus memiliki keahlian khusus untuk membekali siswa memiliki kepedulian lingkungan.

Tabel 2. Sebaran tema tentang lingkungan hidup pada setiap domain IPA di SMA

\begin{tabular}{|l|l|l|l|}
\hline \multicolumn{1}{|c|}{ Kompetensi Dasar } & Kelas X & Kelas XI & Kelas XII \\
\hline Domain IPA & & & \\
\hline Biologi & $3.2 ; 3.10 ; 3.11$ & - & - \\
\hline Fisika & $3.9 ; 4.9$ & $3.12 ; 4.12$ & $3.11 ; 4.11$ \\
\hline Kimia & - & - & - \\
\hline
\end{tabular}

Dari tabel 2, maka pada tingkat SMA pembahasan tema lingkungan secara implisit tidak terdapat dalam nama pokok bahasan atau operasional kompetensi dasar. Namun demikian, muatan tema lingkungan masih dominan pada mata pelajaran-mata pelajaran tersebut. Secara keseluruhan konten materi energi pada setiap jenjang pendidikan dasar dan menengah yang terdapat dalam kurikulum di Indonesia ditunjukkan pada tabel 3 .

Tabel 3. Kompetensi Dasar Konten Materi Energi pada setiap Jenjang Pendidikan Dasar dan Menengah

\begin{tabular}{|c|c|c|}
\hline Mata Pelajaran & Tingkat & Kompetensi Dasar \\
\hline \multirow[t]{2}{*}{ IPA (SD) } & IV & $\begin{array}{l}\text { 3.5 Mengidentifikasi berbagai sumber energi, perubahan bentuk } \\
\text { energi, dan sumber energi alternatif (angin, air, matahari, panas } \\
\text { bumi, bahan bakar organik, dan nuklir) dalam kehidupan sehari- } \\
\text { hari } \\
4.5 \quad \text { Menyajikan laporan hasil pengamatan dan penelusuran } \\
\text { informasi tentang berbagai perubahan bentuk energi } \\
\text { 3.8 Menjelaskan pentingnya upaya keseimbangan dan } \\
\text { pelestarian sumber daya alam di lingkungannya } \\
\text { 4.8 Melakukan kegiatan upaya pelestarian sumber daya alam } \\
\text { bersama orang-orang di lingkungannya }\end{array}$ \\
\hline & $\mathrm{VI}$ & $\begin{array}{l}\text { 3.6 Menjelaskan cara menghasilkan, menyalurkan, dan } \\
\text { menghemat energi listrik } \\
\text { 4.6 Menyajikan karya tentang berbagai cara melakukan } \\
\text { penghematan energi dan usulan sumber alternatif energi listrik }\end{array}$ \\
\hline \multirow[t]{2}{*}{ IPA (SMP) } & VII & $\begin{array}{l}\text { 3.5 Menganalisis konsep energi, berbagai sumber energi, dan } \\
\text { perubahan bentuk energi dalam kehidupan } \\
\text { sehari-hari termasuk fotosintesis } \\
4.5 \quad \text { Menyajikan hasil percobaan tentang perubahan bentuk } \\
\text { energi, termasuk fotosintesis }\end{array}$ \\
\hline & IX & $\begin{array}{l}\text { 3.5 Menerapkan konsep rangkaian listrik, energi dan daya listrik, } \\
\text { sumber energi listrik dalam kehidupan sehari-hari termasuk } \\
\text { sumber energi listrik alternatif, serta berbagai upaya menghemat } \\
\text { energi listrik } \\
4.5 \quad \text { Menyajikan hasil rancangan dan pengukuran berbagai } \\
\text { rangkaian listrik }\end{array}$ \\
\hline Fisika (SMA) & $X$ & $\begin{array}{l}3.9 \text { Menganalisis konsep energi, usaha (kerja), hubungan usaha } \\
\text { (kerja) dan perubahan energi, } \\
\text { hukum kekekalan energi, serta penerapannya dalam peristiwa } \\
\text { sehari-hari }\end{array}$ \\
\hline
\end{tabular}




\begin{tabular}{|l|l|l|}
\hline & $\begin{array}{l}4.9 \text { Menerapkan metode ilmiah untuk mengajukan gagasan } \\
\text { penyelesaian masalah gerak dalam kehidupan sehari-hari, yang } \\
\text { berkaitan dengan konsep energi, usaha (kerja) dan hukum } \\
\text { kekekalan energi }\end{array}$ \\
\hline XII & $\begin{array}{l}.2 \text { Menganalisis muatan listrik, gaya listrik, kuat medan listrik, } \\
\text { fluks, potensial listrik, energi potensial listrik serta penerapannya } \\
\text { pada berbagai kasus }\end{array}$ \\
& $\begin{array}{l}4.2 \text { Melakukan percobaan berikut presentasi hasil percobaan } \\
\text { kelistrikan (misalnya pengisian dan pengosongan kapasitor) dan } \\
\text { manfaatnya dalam kehidupan sehari } \\
\text { 3.11 Menganalisis keterbatasan sumber energi dan dampaknya } \\
\text { bagi kehidupan } \\
\text { 4.11 Menyajikan ide/gagasan dampak keterbatasan sumber } \\
\text { energi bagi kehidupan dan upaya penyelesaian masalah dengan } \\
\text { energi alternatif }\end{array}$ \\
\hline
\end{tabular}

Untuk tingkat perguruan tinggi, pada program studi guru sekolah dasar (studi kasus di PGSD Universitas PGRI Semarang dan Universitas Sebelas Maret) (Patonah \& Rahardjo, 2017). Distribusi konten materi energi pada kedua universitas ditunjukkan pada Tabel 4.

Tabel 4. Bidang kajian IPA pada kurikulum PGSD

\begin{tabular}{|c|c|c|c|}
\hline Mata Kuliah & Semester & SKS & Bidang Kajian \\
\hline Konsep Dasar IPA & 1 & 3 & $\begin{array}{l}\text { 1. Besaran dan pengukuran } \\
\text { 2. Sifat Zat, materi dan perubahannya } \\
\text { 3. Asam, Basa, dan Garam } \\
\text { 4. Gaya dan Gerak } \\
\text { 5. Usaha dan Energi } \\
\text { 6. Suhu Kalor } \\
\text { 7. Mahluk Hidup dan Lingkungannya } \\
\text { 8. Praktikum fisika } 1 \text { dan } 2 \\
\text { 9. Praktikum fisika } 3 \text { dan } 4 \\
\text { 10. Praktikum biologi } 1 \text { dan } 2 \\
\text { 11. Praktikum biologi } 3 \text { dan } 4\end{array}$ \\
\hline $\begin{array}{l}\text { Pengembangan Konsep } \\
\text { Dasar IPA }\end{array}$ & 2 & 3 & $\begin{array}{ll}\text { 1. } & \text { Cahaya dan Bunyi } \\
\text { 2. } & \text { Listrik dan Magnet } \\
\text { 3. } & \text { Tata Surya dan Benda Langit } \\
\text { 4. } & \text { Bioteknologi } \\
\text { 5. } & \text { Hewan Avertebrata dan Vertebrata } \\
\text { 6. } & \text { Sistem Pernafasan } \\
\text { 7. } & \text { Sistem Pencernaan } \\
\text { 8. } & \text { Praktikum fisika } 1 \text { dan } 2 \\
\text { 9. } & \text { Praktikum fisika } 3 \text { dan } 4 \\
\text { 10. } & \text { Praktikum biologi } 1 \text { dan } 2 \\
\text { 11. } & \text { Praktikum biologi } 3 \text { dan } 4 \\
\end{array}$ \\
\hline
\end{tabular}

4. Pembelajaran tentang energi pada penelitian-penelitian sebelumnya

Bagaimana mengajarkan konten energi untuk dapat menumbuhkan kepedulian lingkungan telah dilakukan oleh beberapa peneliti. Berikut penelitian-penelitia bertema energi dibelajarkan pada siswa/ mahasiswa, diantaranya:

a. Bianchini,2000: Membelajarkan menggunakan inquiri dalam 3 bentuk kegiatan yaitu: Baterai dan Umbi, Bubuk Misteri, dan Terapung dan Tenggelamnya(Bianchini \& Colburn, 2000). 
b. Caton, 2000: Membelajarkan sains bagi guru sains dengan berkolaborasi dengan ilmuwan dari universitas(Caton, Brewer, \& Brown, 2000). Guru sains pada tingkat SMP dan SMA berkolaborasi menyiapkan pembelajaran tentang energi. Masing-masing tim membahas tentang penggunaan sumber energi yang dapat menghasilkan energi yang optimal. Diantaranya adalah penggunaan sampah sebagi sumber energi terbarukan. Selama $21 / 2$ jam para tim diminta untuk menghasilkan energi dari angin dengan membuat turbin yang dapat menghasilkan energi yang optimal. Hasil diskusi setiap kelompok kemudian dipresentasikan.

c. Hartley,2012: Membelajarkan energi pada 3 disiplin ilmu, yaitu : fisika,biologi, dan kimia(Hartley, Momsen, Maskiewicz, \& Avanzo, 2012). Mahasiswa diminta untuk membuat persepsi tentang konservasi energi berdasarkan latar belakang disiplin ilmu yang dipelajarinya.

d. Kulo,2012 (Kulo \& Bodzin, 2013) menyusun rencan pembelajaran yang dilaksanakan dengan total waktu 40 hari hanya untuk membahas tentang energi menggunakan GIS (geographic information system). Sampel dalam penelitian adalah siswa kelas 8 dan guru-guru dari siswa kelas 8 di United State.

e. Aydogan, 2015: Menggunakan animasi 3D untuk membelajarkan prinsip kerja energi angin. Pembelajaran dilakukan secara virtual untuk menunjukkan sistem kerja energi angin, merakit, dan mediskusikannya(Aydogan, Karakas, Aras, \& Ozudogru, 2011).

f. Bambara,2015: mengajarkan materi energi melalui pembuatan STPV (semi transparan photovoltaics) pada green house sebagai perangkap panas dan sumber energi(Bambara \& Athienitis, 2015).

g. Pembelajaran tentang energi dengan outing class/ outdoor activity. Siswa/ mahasiswa mengetahui sumber-sumber energi terbarukan yang ada di sekelilingnya serta menumbuhkan kepedulian lingkungan (Grimmette, 2014);(Stoeckel, Esser, Gamer, BÃ $1 / 4$ Chel, \& von Leupoldt, 2015);(Patonah \& Rahardjo, n.d.).

\section{Potensi konten materi energi dalam menumbuhkan kepedulian lingkungan}

Untuk menumbuhkan kepedulian lingkungan pada mahasiswa calon guru SD melalui konten energi ditunjukkan pada Tabel 5.

Tabel 5. Capaian Pembelajaran Energi dalam kurikulum PGSD

\begin{tabular}{|c|c|c|c|c|c|}
\hline \multicolumn{3}{|c|}{$\begin{array}{l}\text { Capaian Pembelajaran dalam Kurikulum PGSD di } \\
\text { Universitas PGRI Semarang }\end{array}$} & \multicolumn{3}{|c|}{$\begin{array}{l}\text { Capaian Pembelajaran dalam Kurikulum } \\
\text { PGSD di Universitas Sebelas Maret }\end{array}$} \\
\hline MK/ SMT & PB & $\mathrm{CP}$ & MK/SMT & PB & $\mathrm{CP}$ \\
\hline $\begin{array}{l}\text { Pengembang } \\
\text { an Konsep } \\
\text { Dasar IPA/2 }\end{array}$ & Energi & $\begin{array}{l}\text {-Mengidentifikasi } \\
\text { energi dalam } \\
\text { kehidupan sehari- } \\
\text { hari } \\
\text {-Mengidentifikasi } \\
\text { sumber-sumber } \\
\text { energi yang ada di } \\
\text { lingkungan sekitar } \\
\text {-Mengidentifikasi } \\
\text { sumber energi dan } \\
\text { penggunaannya }\end{array}$ & $\begin{array}{l}\text { Konsep } \\
\text { Dasar IPA } \\
1 / 2\end{array}$ & $\begin{array}{l}\text { Ekologi } \\
\text { dan } \\
\text { Pencemar } \\
\text { an }\end{array}$ & $\begin{array}{l}\text { Mahasiswa } \\
\text { menguasai } \\
\text { gerak dan } \\
\text { energi gerak }\end{array}$ \\
\hline
\end{tabular}


SHEs: Conference Series 1 (1) (2018) 811-821

\begin{tabular}{|c|c|c|c|}
\hline & & $\begin{array}{lr}\text { serta } & \text { menerapkan } \\
\text { cara menghemat } \\
\text { energi dalam } \\
\text { kehidupan sehari- } \\
\text { hari } \\
\text {-Mengidentifikasi } \\
\text { energi alternatif di } \\
\text { lingkungan sekitar }\end{array}$ & pencemaran \\
\hline $\begin{array}{l}\text { Pendidikan } \\
\text { Lingkungan } \\
\text { Hidup/ } 6\end{array}$ & $\begin{array}{l}\text { Energi } \\
\text { dan } \\
\text { Sumber } \\
\text { Daya } \\
\text { Alam }\end{array}$ & $\begin{array}{l}\text {-Mahasiswa mampu } \\
\text { menjelaskan } \\
\text { pengertian, fungsi, } \\
\text { jenis-jenis, dan } \\
\text { perubahan energi } \\
\text { dalam kehidupan } \\
\text { sehari-hari } \\
\text {-Mahasiswa mampu } \\
\text { menjelaskan } \\
\text { pengertian sumber } \\
\text { daya alam dan } \\
\text { memberikan } \\
\text { contohnya }\end{array}$ & \\
\hline
\end{tabular}

Note: MK : mata kuliah; SMT: semester; PB: Pokok Bahasan; CP: Capaian Pembelajaran

\section{Framework}

Berdasarkan uraian di atas maka potensi konten energi dalam kurikulum PGSD memiliki peran yang strategis untuk menumbuhkan kepedulian lingkungan. Dari mempelajari tentang konsep energi yang benar, mahasiswa memiliki energi literacy, yang pada akhirnya dapat lebih bijak dalam menyelesaikan masalah berkaitan dengan energi dan penggunaannya, kritis mencari sumber-sumber energi alternatif terbarukan untuk berperan serta menjaga kelestarian lingkungan. Secara umum framework atas potensi konten energi untuk menumbuhkan kepedulian lingkungan ditampilkan pada Gambar 1.
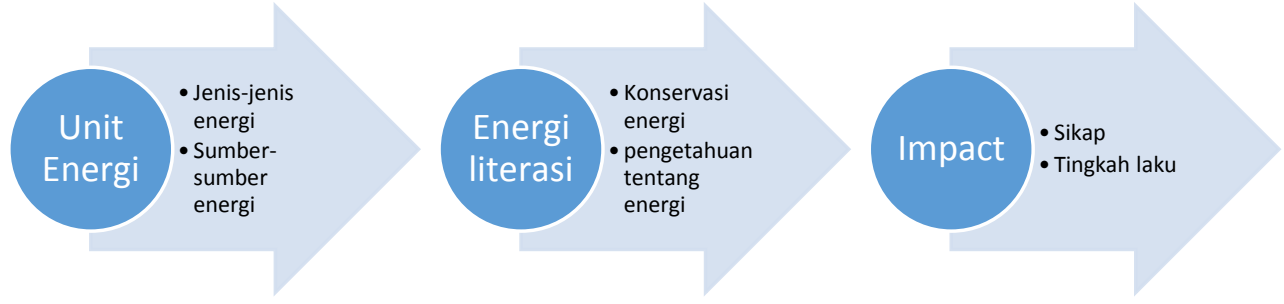

Gambar 1. Bagan Framework energi leterasi 


\section{SIMPULAN}

Memahami konsep energi yang benar dan membimbing seseorang untuk bijak memanfaatkan energi yang ada serta upaya kritis untuk berkontribusi menemukan sumber-sumber energi alternatif yang terbarukan. Bagi calon guru sekolah dasar pemahaman yang betul tentang konsep energi dapat digunakan sebagai bekal yang bermanfaat untuk menyiapkan peserta didik yang tidak hanya mengetahui tetapi dapat diwujudkan dengan perbuatan nyata dalam sikap dan tingkah laku dalam kehidupan sehari-hari.

\section{DAFTAR PUSTAKA}

Abu Md Abdul Wadud, B., Tousif Zaman, M., Rabbee, F., \& Rajibur Rahman, M. (2013). Renewable Energy: An Ideal Solution of Energy Crisis and Economic Development in Bangladesh. Global Journal of Researches in Engineering Electrical and Electronics Engineering, 13(15).

Alrikabi, N. K. M. A. (2014). Renewable Energy Types. Journal of Clean Energy Technologies, 2(1), 61-64. https://doi.org/10.7763/JOCET.2014.V2.92

Alshuwaikhat, H. M., \& Abubakar, I. (2008). An integrated approach to achieving campus sustainability: assessment of the current campus environmental management practices. Journal of Cleaner Production, 16(16), 1777-1785. https://doi.org/10.1016/j.jclepro.2007.12.002

Aydogan, H., Karakas, E., Aras, F., \& Ozudogru, F. (2011). 3D virtual classroom environment for teaching renewable energy production and substation equipment. International Journal of Electrical Engineering Education, 48(3), 294-306. https://doi.org/10.7227/ijeee.48.3.7

Bambara, J., \& Athienitis, A. (2015). Experimental evaluation and energy modeling of a greenhouse concept with semi-transparent photovoltaics. Energy Procedia, 78, 435-440. https://doi.org/10.1016/j.egypro.2015.11.689

Bauman, P. C., \& Petrock, E. M. (1981). Energy Literacy, 1-38.

Bianchini, J. a, \& Colburn, a. (2000). Teaching the nature of science through inquiry to prospective elementary teachers: A tale of two researchers. Journal of Research in Science Teaching, 37(2), 177-209. https://doi.org/10.1002/(sici)10982736(200002)37:2<177::aid-tea6>3.0.co;2-y

Caton, E., Brewer, C., \& Brown, F. (2000). Building Teacher-Scientist Partnerships: Teaching About Energy Through Inquiry. School Science and Mathematics, 100(1), 7-15. https://doi.org/10.1111/j.1949-8594.2000.tb17315.x

Fidan, N. K., \& Ay, T. S. (2016). Acquisition of operational environmental literacy in social studies course. International Journal of Environmental and Science Education, 11(13), 5951-5968.

Freije, A. M., Hussain, T., \& Salman, E. A. (2015). Global warming awareness among the University of Bahrain science students. Journal of the Association of Arab Universities for Basic and Applied Sciences, 9-16. https://doi.org/10.1016/j.jaubas.2016.02.002

Grimmette, K. A. (2014). The Impacts of Environmental Education on Youth and their Environmental Awareness.

Hadzigeorgiou, Y., \& Skoumios, M. (2013). The development of environmental awareness through school science: Problems and possibilities. International Journal of Environmental \& Science Education, 8(3), 405-426. https://doi.org/10.12973/ijese.2013.212a

Hartley, L. M., Momsen, J., Maskiewicz, A., \& Avanzo, C. D. (2012). Energy and Matter: Differences in Discourse in Physical and Biological Sciences Can Be Confusing for Introductory Biology Students. BioScience, 62(5), 488-496. 
https://doi.org/10.1525/bio.2012.62.5.10

Jones, J. K. (2013). Re-discovering the arts: The impact of engagement in a natural environment upon pre-service teacher perceptions of creativity. Thinking Skills and Creativity, 8(1), 102-108. https://doi.org/10.1016/j.tsc.2012.08.001

Karataş, A. (2014). Environmental ethics education as a tool for the prevention of environmental problems in the community. European Journal of Sustainable Development, 3(4), 263-268. https://doi.org/10.14207/ejsd.2014.v3n4p263

Koruoglu, N., Ugulu, I., \& Yorek, N. (2015). Investigation of High School Students Environmental Attitudes in Terms of Some Demographic Variables, (October), 1608-1623.

Kulo, V., \& Bodzin, A. (2013). The Impact of a Geospatial Technology-Supported Energy Curriculum on Middle School Students' Science Achievement. Journal of Science Education and Technology, 22(1), 25-36. https://doi.org/10.1007/s10956012-9373-0

Mei, N. S., Wai, C. W., \& Ahamad, R. (2016). Environmental Awareness and Behaviour Index for Malaysia. Procedia - Social and Behavioral Sciences, 222(07), 668-675. https://doi.org/10.1016/j.sbspro.2016.05.223

NRC. (2006).

Ostrom, E., Dietz, T., Dolsak, N., Stern, P. C., Stonich, S., \& Weber, E. U. (2002). The Drama of the Commons. https://doi.org/10.17226/10287

Palmer, J. (1998). Environmental education in the 21st Century.

Patonah, S., Nuvitalia, D., \& Saptaningrum, E. (2017). 3 1,2,3. In PEMBELAJARAN INQUIRY DAN KETERAMPILAN PROSES SAINS DALAM IMPLEMENTASI KURIKULUM IPA DI SMP.

Patonah, S., \& Rahardjo, S. B. (n.d.). The Potential of Outing Class Activities to Enhance Environmental Awareness for Elementary School Pre- Services Teacher, $1-5$.

Patonah, S., \& Rahardjo, S. B. (2017). POTENSI MELATIHKAN ENVIRONMENTAL LITERACY BAGI CALON, (36), 1-5.

Saribas, D., Teksoz, G., \& Ertepinar, H. (2014). The relationship between environmental literacy and self-efficacy beliefs toward environmental education, 116, 3664-3668. https://doi.org/10.1016/j.sbspro.2014.01.820

Sarsour, A., \& Ayoub, A. (2015). Full Length Research Paper A Preliminary Assessment for the Environmental Awareness of the Universities ' Students in Gaza strip- Palestine, 3(3), 85-93.

Simon, H. a. (1973). Technology and Environment. Management Science (Vol. 19). https://doi.org/10.1287/mnsc.19.10.1110

Stern, P. C., Young, O. R., \& Druckman, D. (1992). Global environmental change: Understanding the human dimension.

Stoeckel, M. C., Esser, R. W., Gamer, M., BÃ¹/4chel, C., \& von Leupoldt, A. (2015). Brain mechanisms of short-term habituation and sensitization toward dyspnea. Frontiers in Psychology, 6(June), 1-8. https://doi.org/10.3389/fpsyg.2015.00748

Systems, E., \& Sciences, P. (2017). Utilizing the Energy Resource Potential of DOE Lands. https://doi.org/10.17226/24825

Toom, A., Pietarinen, J., Soini, T., \& Pyhältö, K. (2017). How does the learning environment in teacher education cultivate first year student teachers' sense of professional agency in the professional community? Teaching and Teacher Education, 63, 126-136. https://doi.org/10.1016/j.tate.2016.12.013

Uzunöz, F. S., \& Demirhan, G. (2017). The effect of creative drama on critical thinking in preservice physical education teachers. Thinking Skills and Creativity, 24, 164174. https://doi.org/10.1016/j.tsc.2017.02.018

Yuan, X., She, M., Li, Z., Zhang, Y., \& Wu, X. (2016). Mutual awareness: Enhanced by interface design and improving team performance in incident diagnosis under 
computerized working environment. International Journal of Industrial Ergonomics. https://doi.org/10.1016/j.ergon.2016.05.001

Yumuşak, A., Sargın, S. A., Baltacı, F., \& Kelani, R. R. (2016). Science and Mathematics Teacher Candidates' Environmental Knowledge, Awareness, Behavior and Attitudes. International Journal of Environmental \& Science Education, 11(6), 1337-1346. https://doi.org/10.12973/ijese.2016.347a 